\title{
Alkaline diagenesis and its genetic mechanism in the Triassic coal measure strata in the Western Sichuan Foreland Basin, China
}

\author{
Jiang Zaixing ${ }^{1 *}$, Qiu Longwei ${ }^{2}$ and Chen Guiju ${ }^{3}$ \\ ${ }^{1}$ College of Energy, China University of Geosciences, Beijing 100083, China \\ ${ }^{2}$ College of Earth Resources and Information, China University of Petroleum, Shandong 257062, China \\ ${ }^{3}$ Sinopec Exploration and Production Research Institute, Beijing 100083, China
}

\begin{abstract}
The reservoir of the upper Triassic Xujiahe Formation $\left(\mathrm{T}_{3} \mathrm{x}\right)$ in the Western Sichuan Foreland Basin is a set of terrigenous clastic rocks in an environment of coal measure sediments. Diagenesis greatly controls the physical properties of the reservoir through different responses of minerals to acidic and alkaline diagenetic environment. The dissolution of unstable components such as feldspar, rock fragments, carbonate cement, and clay minerals is the major source of secondary pores under acidic diagenesis, while the dissolution of quartz increases the reservoir space in the fault-fold zone of Longmen Mountain and Leikoupo paleo-hills. The dissolution of quartz is a result of cross-formation flow of fluid in the Himalaya epoch and the invasion of alkaline formation water from the Triassic Leikoupo and Jialingjiang formations through fault and fracture systems. In the vertical succession, acidic dissolution occurs at a shallow depth of less than $2,180 \mathrm{~m}$, and alkaline dissolution occurs at a greater depth of more than $2,280 \mathrm{~m}$. The reservoir space is formed by the influence of both acidic and alkaline dissolution in the depth interval of 2,180-2,280 m.
\end{abstract}

Key words: Sichuan Basin, upper Triassic, alkaline diagenesis, porosity, genetic mechanism

\section{Introduction}

The reservoir of the upper Triassic Xujiahe Formation $\left(\mathrm{T}_{3} \mathrm{x}\right)$ in the Sichuan Foreland Basin consists of terrigenous clastic rocks in an environment of coal measure strata. Coal measure strata are important source rocks as well as reservoirs for oil and gas (Zheng and Ying, 1997). The strata are rich in humic organic matter and in the early paludification (peat bog expansion) stages and the following maturation, the concentration of organic acid is high and carbonate is dissolved at an early stage. Carbonate and feldspar are dissolved to generate a large amount of secondary pores in such process (Surdam et al, 1985; 1989; Zheng and Ying, 1997). Many factors influence the pore evolution of a clastic reservoir, including physical and chemical factors such as temperature (Fang et al, 2002), pressure (Hunt, 1990; Wilkinson et al, 1997; Osborne and Swarbrick, 1999), fluid property, and the sealing and opening of the system $(\mathrm{Mu}$ and Zhang, 1994). Among these factors, the fluid properties play a key role in dissolution and precipitation of minerals (Qiu and Jiang, 2006). Most studies have considered that secondary porosity is generated by the dissolution of unstable minerals due to carbonic acid and organic acid (Pang and Zheng, 1989; Bloch, 1994; Xu and Lu, 1994; Giles, 1997; Zhuang et al,

*Corresponding author. email: jiangzx@cugb.edu.cn

Received January 6, 2009
1998; You and Zheng, 1999; Bloch et al, 2002), but stable quartz is characterized by secondary overgrowth (Oelkers et al, 1992; Bjørkum et al, 1998) that reduces the porosity and permeability of the sandstone reservoir.

Generally speaking, it is difficult for quartz and lithic quartzite to dissolve. People tend to believe that the dissolution of quartz is not direct, but it happens from later dissolution of acid-unstable materials such as carbonate cements that replaced quartz in the early stage of diagenesis. However, laboratory experiments have indicated that quartz can be dissolved directly (Knauss and Wolery, 1988; Hiemstra and Van Riemsdijk, 1990; Brady, 1992; Zhang and Li, 1996). Riley et al (2002) found that secondary pores include the pores from feldspar dissolution and a large number of pores from quartz dissolution. Southwick (1985) reported that quartz and other silicate minerals were dissolved by alkaline solutions. This study found that in some regions the quartz in the reservoir directly dissolved to generate secondary pores. This requires explanation in view of the generally acidic sedimentary coal measure strata environment of the reservoir.

It is found that the density of organic acid in the coal sample is $11 \mathrm{mg} / \mathrm{g}-95 \mathrm{mg} / \mathrm{g}$ and the density of organic acid in the kerogen in fresh and brackish water is $30 \mathrm{mg} / \mathrm{g}-60 \mathrm{mg} / \mathrm{g}$ (Zheng and Ying, 1997). However, when quartz is dissolved, the formation water should be mildly or strongly alkaline. So it is important to make clear the factors that control the direct dissolution of quartz in such an environment and the 
distribution of quartz dissolution porosity in diagenesis. Such knowledge will benefit our understanding of the genesis of secondary porosity in reservoirs.

\section{Geological background}

\subsection{Tectonic background}

The Western Sichuan Foreland Basin, with an area about
$80,000 \mathrm{~km}^{2}$, is located in the frontal zone of the Longmen and Micang-Daba mountains. The basin's boundaries are the Longmen Mountain Fault to the west, the Qiyue Mountain Fault to the east, the Emei-Washan Fault to the south, and the Chengkou Fault to the north (Fig. 1). They are all large faults that deeply cut the earth's crust. From west to east, the structural zonation is a foreland thrust zone, a fore-deep depression, a foreland slope, and an uplift zone (Fig. 1).

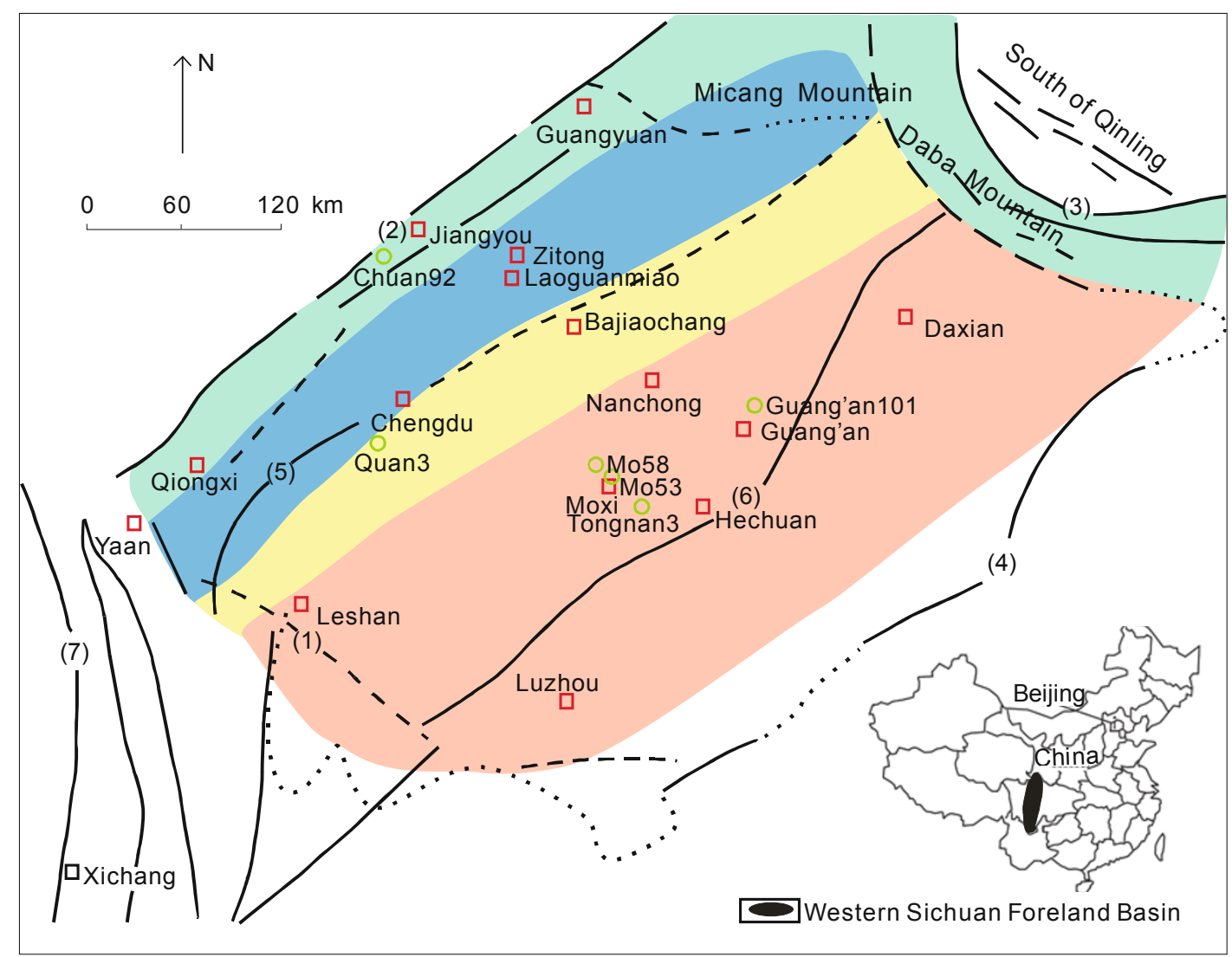

(1) Emei-Washan Fault (2) Longmen Mountain Fault (3) Chengkou Fault (4) Qiyue Mountain Fault (5) Xiongpo Fault (6) Huaying Mountain Fault (7) Anning River Fault

Foreland thrust zone $\square$ Fore-deep depression

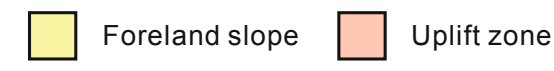

$\square$ Location name

Well name

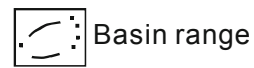

Fig. 1 Tectonic outline of the Western Sichuan Foreland Basin

\subsection{Stratigraphy and basin evolution}

The upper Triassic Xujiahe Formation, or $\mathrm{T}_{3} \mathrm{x}$, unconformably overlies limestones, dolomites, mud/shale, and gypsum of the middle Triassic Leikoupo Formation (Tr), and is overlain by Jurassic red terrigenous clastic rocks (Fig. 2).

The $T_{3} \mathrm{x}$ is a set of grey strata consisting of pebbly sandstones, sandstones, siltstones, mudstones, and coal. In vertical profile, the sandstones and mudstones constitute rhythmic layering of non-uniform thickness. According to outcrops, drilling and well-logging data, the $\mathrm{T}_{3} \mathrm{x}$ can be subdivided into six members, i.e., from $T_{3} x^{1}$ to $T_{3} x^{6}$. The source rocks are in $\mathrm{T}_{3} \mathrm{x}^{1}, \mathrm{~T}_{3} \mathrm{x}^{3}$, and $\mathrm{T}_{3} \mathrm{x}^{5}$, and reservoirs are mainly in $T_{3} x^{2}, T_{3} x^{4}$, and $T_{3} x^{6}$.

The generation and evolution of the upper Triassic in the Western Sichuan Foreland Basin are mainly controlled by thrusting and ductile movement of the deep crust and can be divided into three periods:

1) In the $T_{3} x^{1}$ period (the end of the Karnian period), the Western Sichuan Foreland Basin began to form from the tectonic activity of the Indo-China epoch at the end of the middle Triassic (Fig. 2). The strong tectonic movement generated a NE-strike geotectogene in the western Sichuan area which was the embryonic form for the foreland basin.

2) During the $T_{3} x^{2}-T_{3} x^{3}$ period (late Nuoli period), the 


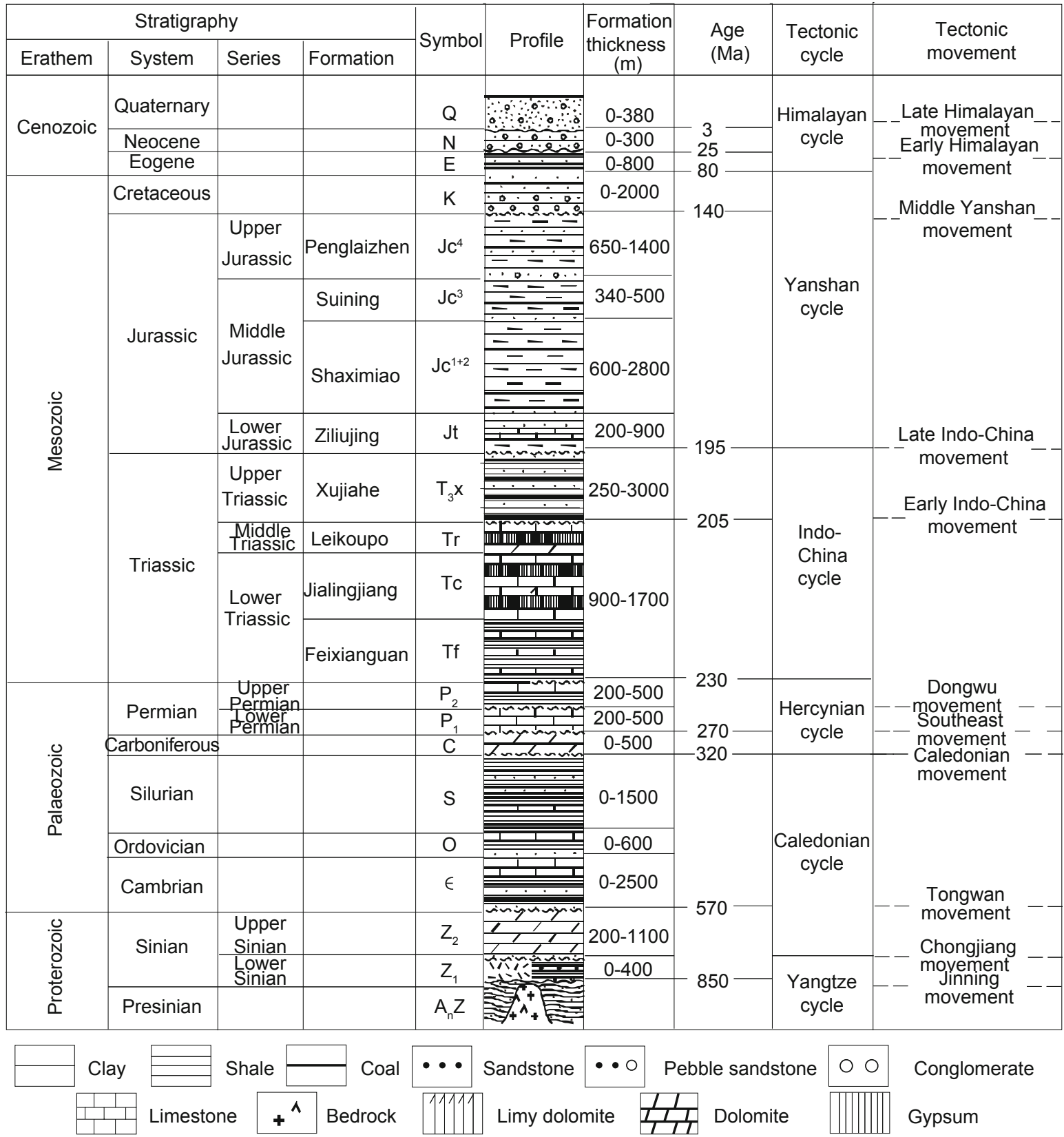

Fig. 2 Stratigraphy and tectonic movements of the Western Sichuan Foreland Basin

foreland basin at the edge of Songpan-Ganzi was strongly folded and mainly underwent compression and depression, and sedimentation began.

3) During the $T_{3} x^{4}-T_{3} x^{6}$ period (Rhaetian period), large amounts of sediments dispersed into the basin. Since then the Western Sichuan Foreland Basin has formed.

At the end of the late Triassic, influenced by the late IndoChina tectonic event, most of the basin was uplifted and eroded, the unconformity between the Jurassic and the upper Triassic formed, the foreland basin of the upper Triassic withered away, and the basin entered a stage of depression (Fig. 2).

\subsection{Sedimentary facies and development}

The upper Triassic in the Western Sichuan Foreland Basin can be divided into four 3 rd-order sequences and twelve systems tracts (Jiang et al, 2007). Four areas including the Longmen Mountain, Micang-Daba Mountain, Kangdian, and Jiangnan paleolands comprise the detrital provenance areas. Eight sedimentary facies were developed, i.e., estuary alluvial fan, meandering river, braided stream, fan delta, fluvial dominant delta, lacustrine facies, and sublacustrine fan.

During the deposition of sequence I, which approximately corresponded to $\mathrm{T}_{3} \mathrm{x}^{1}$ and the lower part of $\mathrm{T}_{3} \mathrm{x}^{2}$, the basin was transformed from marine-continental transitional facies to continental facies, and estuarine and tidal flat facies were developed in this period.

The unified inland basin was formed during the deposition of sequence II, which approximately corresponded to $\mathrm{T}_{3} \mathrm{x}^{3}$ and the upper part of $\mathrm{T}_{3} \mathrm{x}^{2}$. Its transgression was the most extensive during the deposition of the Xujiahe Formation. Deltaic and lacustrine facies were developed during this 
period.

During the deposition of sequence III, which approximately corresponded to $\mathrm{T}_{3} \mathrm{x}^{4}$ and the lower part of $\mathrm{T}_{3} \mathrm{x}^{5}$, abundant sediments were provided by the Micang-Daba Mountains. Alluvial fan, braided fluvial, and braided fluvial delta facies were well developed along the Micang-Daba Mountain frontal thrust zones.

During the deposition of sequence IV, which approximately corresponded to $\mathrm{T}_{3} \mathrm{x}^{6}$ and the upper part of $\mathrm{T}_{3} \mathrm{x}^{5}$, deltaic and lacustrine facies were developed. The distribution of sedimentary facies in the Western Sichuan Foreland Basin was mainly determined by tectonics, and the facies were distributed parallel to the structural belt. A coarse-grained alluvial fan, a fan delta and a sublacustrine fan developed along the northwestern steep slope belt, and a braided fluvial delta developed along the southwestern steep slope belt and the northern-northeastern steep slope belt. Meandering fluvial and meandering fluvial delta facies developed in the southeastern ramp slope belt.

\section{Evidence for acidic and alkaline diagenesis}

\subsection{Characteristics of the formation water}

The formation water from gas-producing $\mathrm{T}_{3} \mathrm{x}^{2}$ has a $\mathrm{pH}$ value of 11 in well Chuan92 and a pH value of 9 in well Quan 3 , and the average $\mathrm{pH}$ is 10 for three samples, which is even higher than that of Leikoupo and Jialingjiang formations. The $\mathrm{pH}$ values of $\mathrm{T}_{3} \mathrm{x}^{4}$ and $\mathrm{T}_{3} \mathrm{x}^{5}$ are about 5.9 and 4.3 respectively. The $\mathrm{pH}$ value of the formation water from $\mathrm{T}_{3} \mathrm{x}^{6}$ is 9.5 in the well Tongnan 3 and 8.6 in the well Guang'an101, and the average $\mathrm{pH}$ for $\mathrm{T}_{3} \mathrm{x}^{6}$ is 7.79 (Table 1).

Table $1 \mathrm{pH}$ values of formation water in the western Sichuan area

\begin{tabular}{|c|c|c|c|}
\hline Formation & Member & $\mathrm{pH}$ & Number of samples \\
\hline \multirow{6}{*}{ Xujiahe } & $\mathrm{T}_{3} \mathrm{x}^{6}$ & 7.79 & 3 \\
\hline & $\mathrm{T}_{3} \mathrm{x}^{5}$ & 4.315 & 12 \\
\hline & $\mathrm{T}_{3} \mathrm{x}^{4}$ & 5.908 & 13 \\
\hline & $\mathrm{T}_{3} \mathrm{x}^{3}$ & & \\
\hline & $\mathrm{T}_{3} \mathrm{x}^{2}$ & 10 & 3 \\
\hline & $\mathrm{T}_{3} \mathrm{x}^{1}$ & & \\
\hline \multirow{2}{*}{ Leikoupo } & $\operatorname{Tr}^{2}$ & 7.793 & 1 \\
\hline & $\operatorname{Tr}^{1}$ & 7.672 & 3 \\
\hline \multirow{5}{*}{ Jialingjiang } & $\mathrm{Tc}^{5}$ & 7.52 & 3 \\
\hline & $\mathrm{Tc}^{4}$ & & \\
\hline & $\mathrm{Tc}^{3}$ & & \\
\hline & $\mathrm{Tc}^{2}$ & 5.927 & 32 \\
\hline & $\mathrm{Tc}^{1}$ & & \\
\hline \multirow{2}{*}{ Feixianguan } & $\mathrm{Tf}^{2}$ & 5.623 & 2 \\
\hline & $\mathrm{Tf}^{1}$ & 4.627 & 1 \\
\hline
\end{tabular}

The above data reveal that the acidity of the formation water is not always determined by the coal measure strata. In some regions, alkaline formation water does exist in $\mathrm{T}_{3} \mathrm{x}$, because alkaline formation water was active and could influence the reservoir rocks in the diagenesis stage even in a coal measure environment. The members that overlie the Leikoupo Formation tend to be more alkaline, which means that the alkaline formation water might come from the underlying strata of the Leikoupo and upper Jialingjiang formations.

\subsection{Evidence for acidic diagenesis}

Dissolution by acidic formation water is a process in which unstable components such as feldspar, rock fragments and carbonate dissolve to produce secondary pores. There are areas such as Zitong and Qiongxi in the southwest of the basin close to the source kitchen (Fig. 1), and the thickness of source rocks in these areas in the upper Triassic is from $100 \mathrm{~m}$ to $1,000 \mathrm{~m}$. So a large amount of organic acid might be produced during the maturation of organic matter, thus it is easy for unstable components to dissolve. The dissolution phenomena of the unstable components, such as partial dissolution, moldic pores, grain-edge pores, and oversized pores mean that strong acidic dissolution has taken place in the study area (Fig. 3). The phenomena are mainly described as follows:

1) Intragranular dissolution pores: Such pores are mainly developed within feldspar or lithic fragments. It is common to see the residual minerals due to the dissolution of potassium feldspar along its crystal twinning, as well as filiform residual minerals from the dissolution of lithic fragments. The pore shapes are irregular and honeycombed. Intragranular dissolution pores are one of the main reservoir space types (Fig. 3(a)).

2) Pores along a detrital particle: Such pores appear between authigenic minerals and detrital particles. They are not residual pores after authigenic mineral deposition, but are dissolution pores from the cement that adjoins the detrital particles (Fig. 3(b)).

3) Oversized dissolution pores: Such pores are formed by dissolved feldspar and lithic particles (Fig. 3(c)).

4) Moldic pores: Such pores are formed when an entire detrital particle is dissolved, leaving an incrust after dissolution such as a chlorite lining. Most moldic pore look like feldspar laths because most dissolution pores are the result of feldspar dissolution (Fig. 3(d)).

\subsection{Evidence for alkaline diagenesis}

\subsubsection{Direct evidence for alkaline diagenesis}

The dissolution of quartz in the $\mathrm{T}_{3} \mathrm{x}$ reservoir in the Western Sichuan Foreland Basin is common because of the role of alkaline water. The evidence of such kind of dissolution is as follows:

1) Partial dissolution: Part of the quartz grains are dissolved and are split into co-extinction micro-grains, sometimes it looks like the remains of the quartz grains (Fig. 4(a)).

2) Dissolution of the grain edge along the contact: 

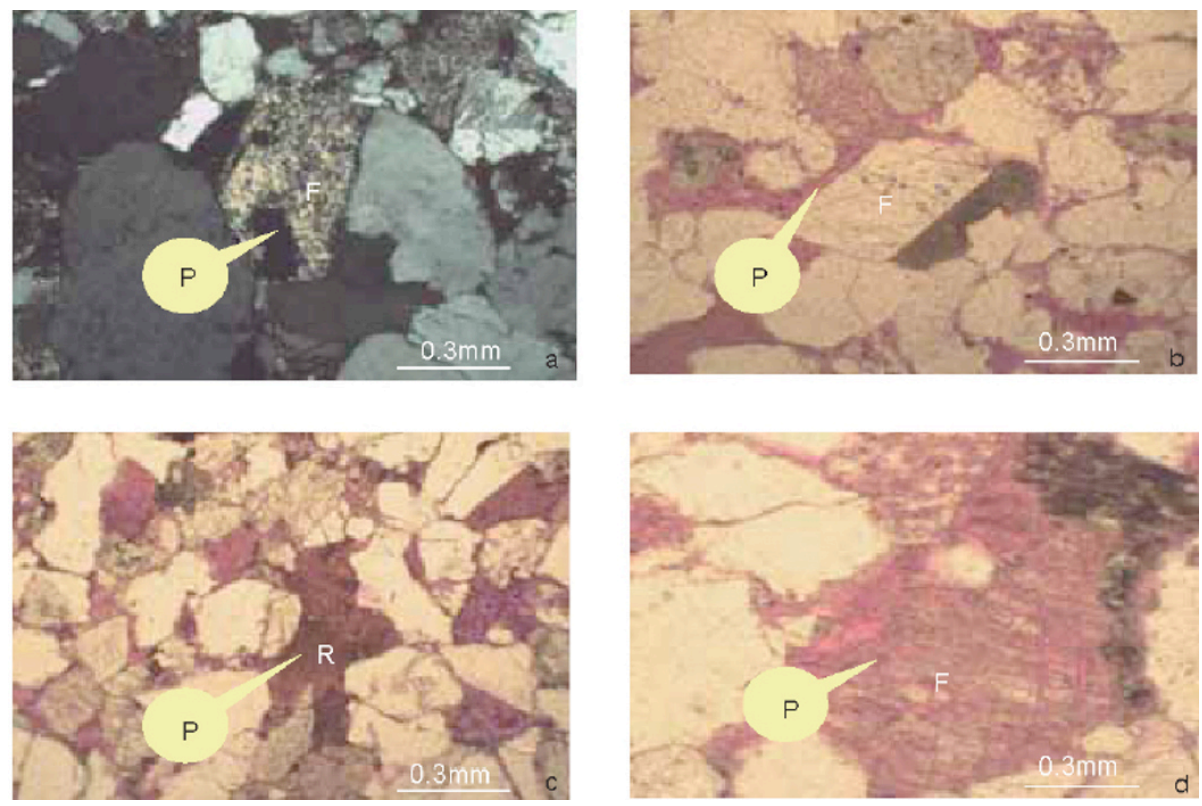

Fig. 3 Microscopic acidic dissolution pores of the $T_{3} x$ sandstones. Red areas in some images are casting plastic filling pores in the thin sections a: Coarse-grained arkose, feldspar grain sericitization, intragranular dissolution pores of feldspar grains, cross-polarization from the Mo53 well at 2,035.7 m b: Coarse-grained feldspathic litharenite, dissolution generated at the junction of grains, forming grain-edge pores; intergranular and intragranular dissolution pores are present in the thin casting sections, from the Mo58 well at 2,158 m

c: Medium-grained lithic arkose, dissolved feldspar and a lithic grain formed an oversized dissolution pore, from the Mo58 well at 2,215.1 m d: Coarse-grained lithic arkose, the moldic pore is due to the dissolution of the feldspar grain twinned lattice, from the Mo58 well at 2,158 m F: feldspar; R: lithic fragments; P: dissolution pore

The edge of the quartz grains is dissolved. Because of the compaction and pressure dissolution of the reservoir, the contact is mainly linear, concave-convex, and sutural, but sometimes mosaic, which damages the pore space. However, at the grain contact region, quartz dissolution is often found to obviously increase the size of the intergranular pores (Fig. 4(b)).

3) Honeycombed pore: Such pores are often present in chert or lithic quartz arenite and are the result of dissolution along the micro-seam in the lithic fragments (Fig. 4(c)).

4) The dissolution of quartz along a micro-fracture: Dissolution along a micro-fracture of the reservoir enlarges the fracture. The fractures not only promote the dissolution of unstable minerals in acidic water but also promote the dissolution of the unstable minerals in alkaline water, and can improve the porosity and permeability of the reservoir (Fig. 4(d)).

\subsubsection{Indirect evidence for alkaline diagenesis}

Indirect evidence for alkaline diagenesis falls into three main points for discussion.

1) Calcite replaces quartz (Fig. 4(e)). The main factors controlling the mutual replacement between $\mathrm{SiO}_{2}$ and $\mathrm{CaCO}_{3}$ are $\mathrm{pH}$ and temperature (Pang and Zheng, 1989). With an increase in $\mathrm{pH}$, the solubility of $\mathrm{SiO}_{2}$ increases, while the solubility of $\mathrm{CaCO}_{3}$ increases with a decrease in $\mathrm{pH}$ value. When the $\mathrm{pH}$ value is lower than 7 , calcite $\left(\mathrm{CaCO}_{3}\right)$ is easily dissolved while silica $\left(\mathrm{SiO}_{2}\right)$ is stable. Therefore, calcite dissolves and the silica in solution deposits in the pore and thus quartz replaces calcite. When the $\mathrm{pH}$ value is higher than $7, \mathrm{SiO}_{2}$ tends to be unstable and is dissolved in burial environments of high temperature, high pressure and ionic concentration. However, under such an environment, $\mathrm{CaCO}_{3}$ is stable and tends to precipitate in pores, so calcite replaces quartz. The replacement is caused by an increase in $\mathrm{pH}$ and temperature of the solution in the pore and a decrease in $\mathrm{CO}_{2}$ (Pang and Zheng, 1989). That is, only when the formation water is alkaline can calcite replace quartz.

2) Alkaline clay minerals. SEM was used to study secondary minerals formed in pores. These were found to consist of illite (Fig. 4(f)). Besides, the main components of clay minerals in the sandstone matrix consist of chlorite and illite. In the process of diagenesis, an alkaline medium is necessary for chlorite and illite to be stable and precipitate, but they will be unstable and transformed into kaolinite in an acidic medium. Formation of chlorite requires a $\mathrm{pH}$ of 8-9. For illite, the $\mathrm{pH}$ value is 9-9.5 (Dong, 1994).

3) Overgrowth of feldspar in the reservoir is common (Fig. 4(g)). The overgrown margin of feldspars reaches $0.03-0.06 \mathrm{~mm}$ in width. It is difficult to generate these wide overgrowths if there is no long-term action of alkaline water because feldspar is an unstable mineral and tends to dissolve in acidic water. In addition, albite can replace calcite cement (Fig. 4(h)), indicating an alkaline environment.

4) The evolution characteristics of authigenic clay minerals. The authigenic clay minerals are products of burial diagenesis, which have the direct and obvious influence on the reservoir physical properties. Different characteristics of formation water control different vertical distribution of 

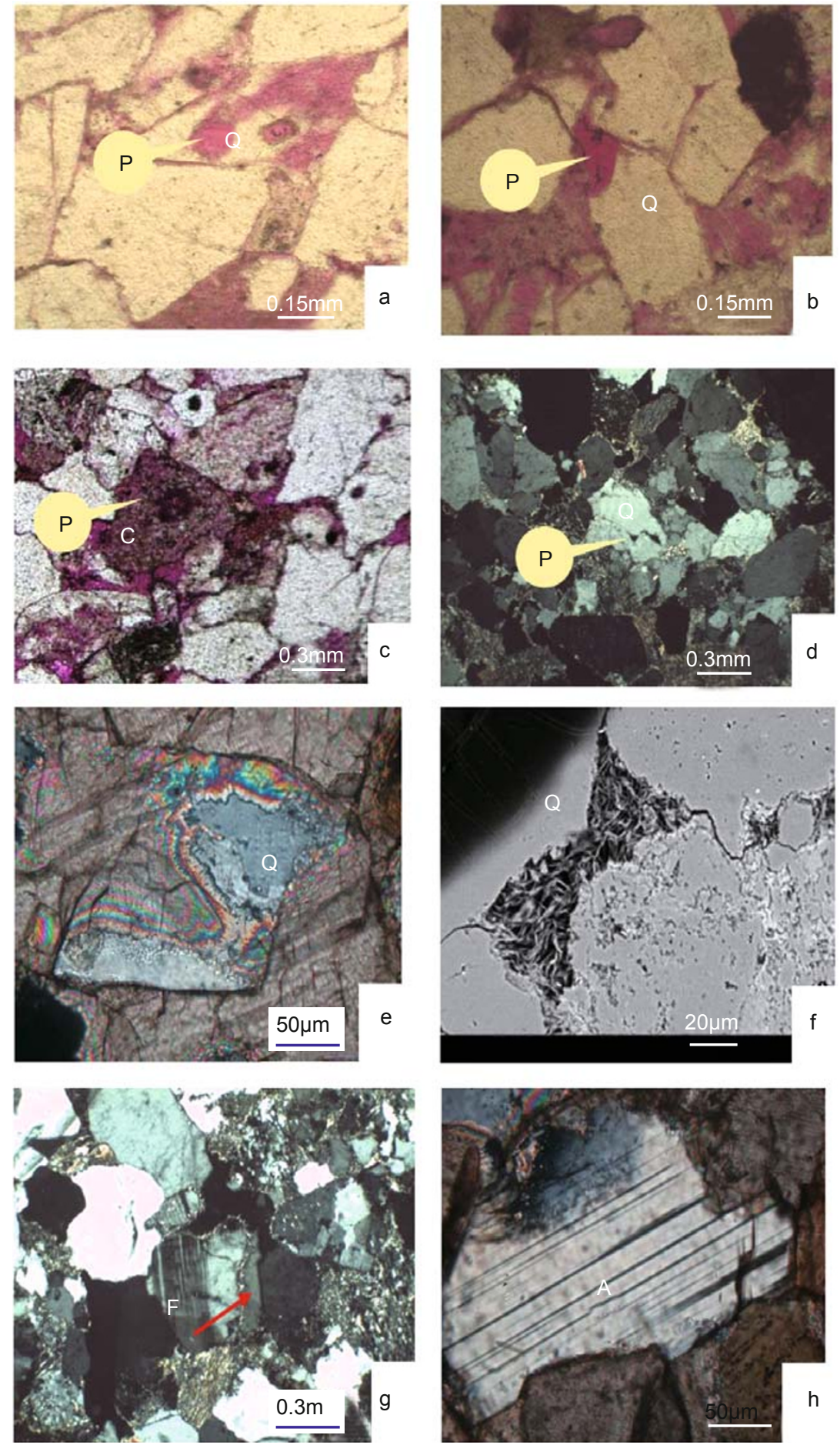

Fig. 4 Microscopic evidence for alkaline dissolution pores. Red areas in some images are casting plastic filling pores in the thin sections a: Medium-grained arkose, intragranular dissolution pores of quartz grain, from the Mo58 well at 2,215.1 m

b: Medium-grained lithic arkose, pores are due to the dissolution of the quartz grain edge, Mo58 well at 2,215.1 m

c: Coarse-grained feldspathic litharenite, the honeycomb pore is from the dissolution of chert, Mo58 well at 2,158 m

d: Fine-grained lithic arkose, micro-fractures are in favor of quartz dissolution (cross polarization), Mo53 well at 2,202.5 m

e: Fine-grained lithic arkose, calcite cement replaces quartz mineral (cross polarization), Mo53 well at 2,202.5 m

f: SEM image showing secondary clay minerals filling the pore, Mo58 well at 2,215.1 m

g: Medium-grained lithic arkose, feldspar authigenic overgrowth leading to a reduction of porosity (cross polarization), Mo58 well at 2,215.1 m

h: Albite replaces calcite cement (cross polarization), Mo53 well at 2,202.5 m

A: albite; C: chert; F: feldspar; P: dissolution pore; Q: quartz

authigenic clay minerals, and control the types and contents of the clay minerals. It can be found from Fig. 5 that illite is the only authigenic clay mineral of $\mathrm{T}_{3} \mathrm{x}^{2}$, while authigenic clay minerals of $\mathrm{T}_{3} \mathrm{x}^{4}$ are not only illite and chlorite, but also kaolinite. So we can safely infer that an alkaline environment existed in some areas of $\mathrm{T}_{3} \mathrm{x}^{2}$ (Sun et al, 2008; Sun, 2006). 

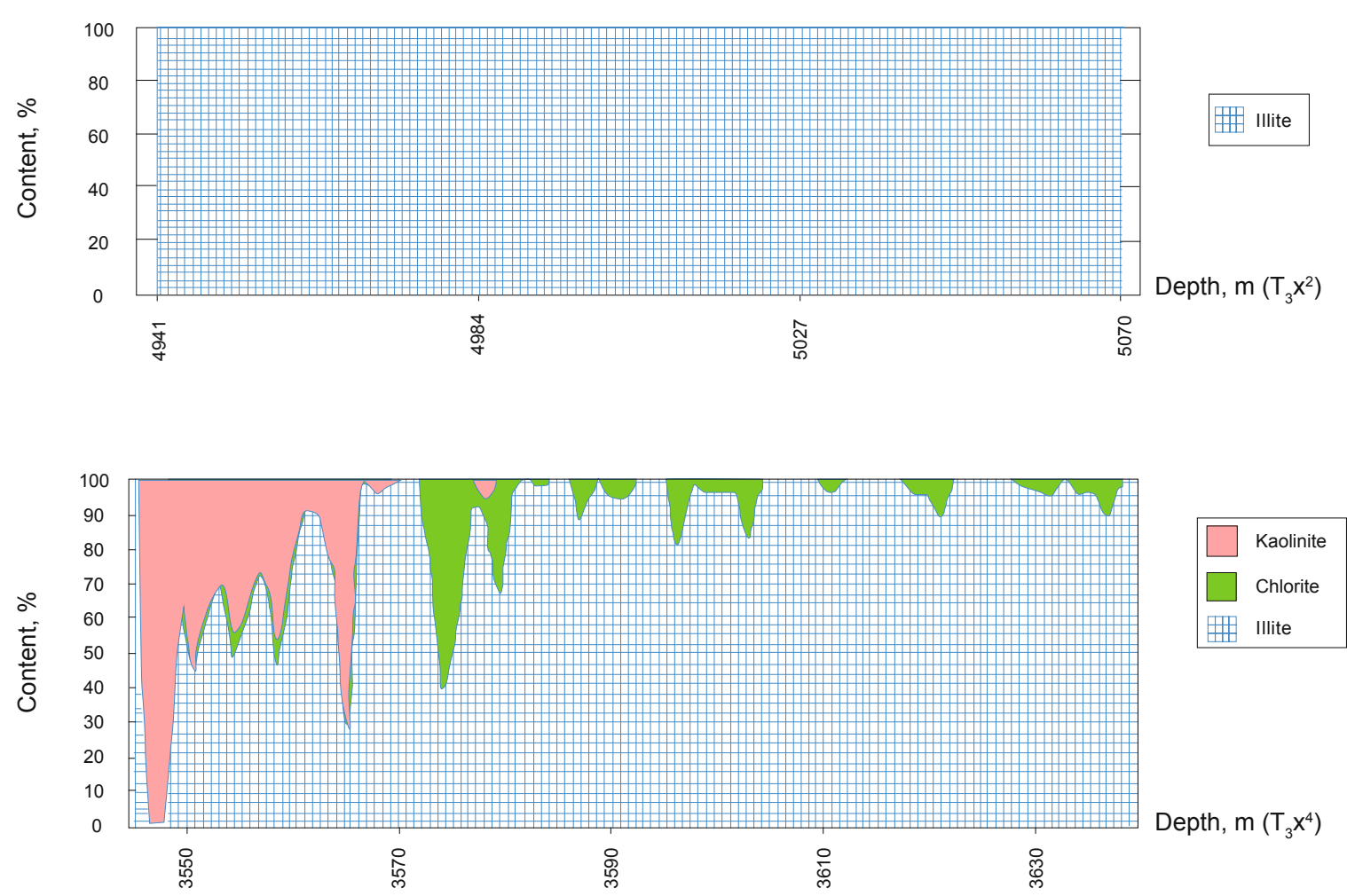

Fig. 5 Vertical distribution of authigenic clay minerals vs. burial depth of sandstone reservoir for $\mathrm{T}_{3} \mathrm{x}^{2}$ (upper) and $\mathrm{T}_{3} \mathrm{x}^{4}$ (lower)

\section{Reservoir characteristics}

The reservoirs of $\mathrm{T}_{3} \mathrm{x}$ are characterized by wide ranges of low porosity and permeability. Porosity ranges from $2 \%$ to $17 \%$ with an average of $6.38 \%$. Permeability ranges from $0.1 \times 10^{-3} \mu \mathrm{m}^{2}$ to $1.0 \times 10^{-3} \mu \mathrm{m}^{2}$ with an average of $0.33 \times 10^{-3} \mu \mathrm{m}^{2}$. The porosity and permeability generally have a positive relation. In a physical property analysis, $70 \%$ of the samples have a porosity of less than $8 \%$. The grain size has a great influence on reservoir properties. Coarse, medium, and fine sandstones often have high, medium, and low porosity, respectively, but conglomerate has the lowest porosity. Due to the acidic and alkaline dissolution, the average porosity of the $\mathrm{T}_{3} \mathrm{x}^{2}$, although it is more deeply buried, is approximately equal to that of the $\mathrm{T}_{3} \mathrm{x}^{4}$. For example, the average porosity of the $\mathrm{T}_{3} \mathrm{x}^{2}$ layer of Mo58 in the Moxi region is $7.50 \%$, while the average porosity of the $\mathrm{T}_{3} \mathrm{x}^{4}$ is $7.55 \%$.

In the Moxi Gas Field, which is located in the uplift zone of the Western Sichuan Foreland Basin (Fig. 1), it is found that the main factor producing secondary pores in the depth range of 2,030-2,060 $\mathrm{m}$ is the dissolution of feldspar and lithic fragments in an acidic environment (Fig. 6). However, in the depth of 2,180-2,280 m, there are two mechanisms generating secondary pores, i.e., the dissolution of unstable components by acidic water and the dissolution of quartz and chert by alkaline water. In the depth range of 2,280-2,340 m, the secondary pores are mainly caused by the dissolution of quartz in an alkaline environment (Fig. 6).

The main type of the reservoir space in the $T_{3} x$ in the northwest of the Sichuan Basin is intergranular pores. Intergranular and intragranular pores and micro-fractures dominate the porosity in the west and southwest parts of the basin. In the basin center, the main pore types include residual porosity, intergranular and intragranular pores in feldspar and volcanic lithic fragments, and a little intercrystalline microporosity in clay minerals. At the same time, the existence of micro-fractures in the gentle tectonic zone in the basin center has positively influenced the reservoir space. At the lower part of the reservoir bed in the $T_{3} x$, the dissolution of quartz grains plays an important role in the amplification of the intergranular and intragranular pores.

\section{Evolution of the formation water}

The acidic and alkaline diagenesis environments result from the sedimentary environment, formation structure, and water-rock interaction in the burial process (Qiu and Jiang, 2006). The environment of the Triassic coal measures should be an acidic background. However, the occurrence of quartz dissolution, which indicates an alkaline environment in such formation water, is puzzling. Three aspects are analyzed to suggest the source of the alkaline water in the area.

\subsection{Formation structure}

The middle Triassic Leikoupo Formation (Tr) with an unconformable contact with the overlying upper Triassic formation, was deposited in a stable sedimentary environment. It inherits the sedimentary characteristics of multi-cycle transgression and regression that belongs to the Jialingjiang Formation of the lower Triassic (Tc). As a result, there are many positive lithological combinations of limestone, dolomite, and evaporite to provide an alkaline 


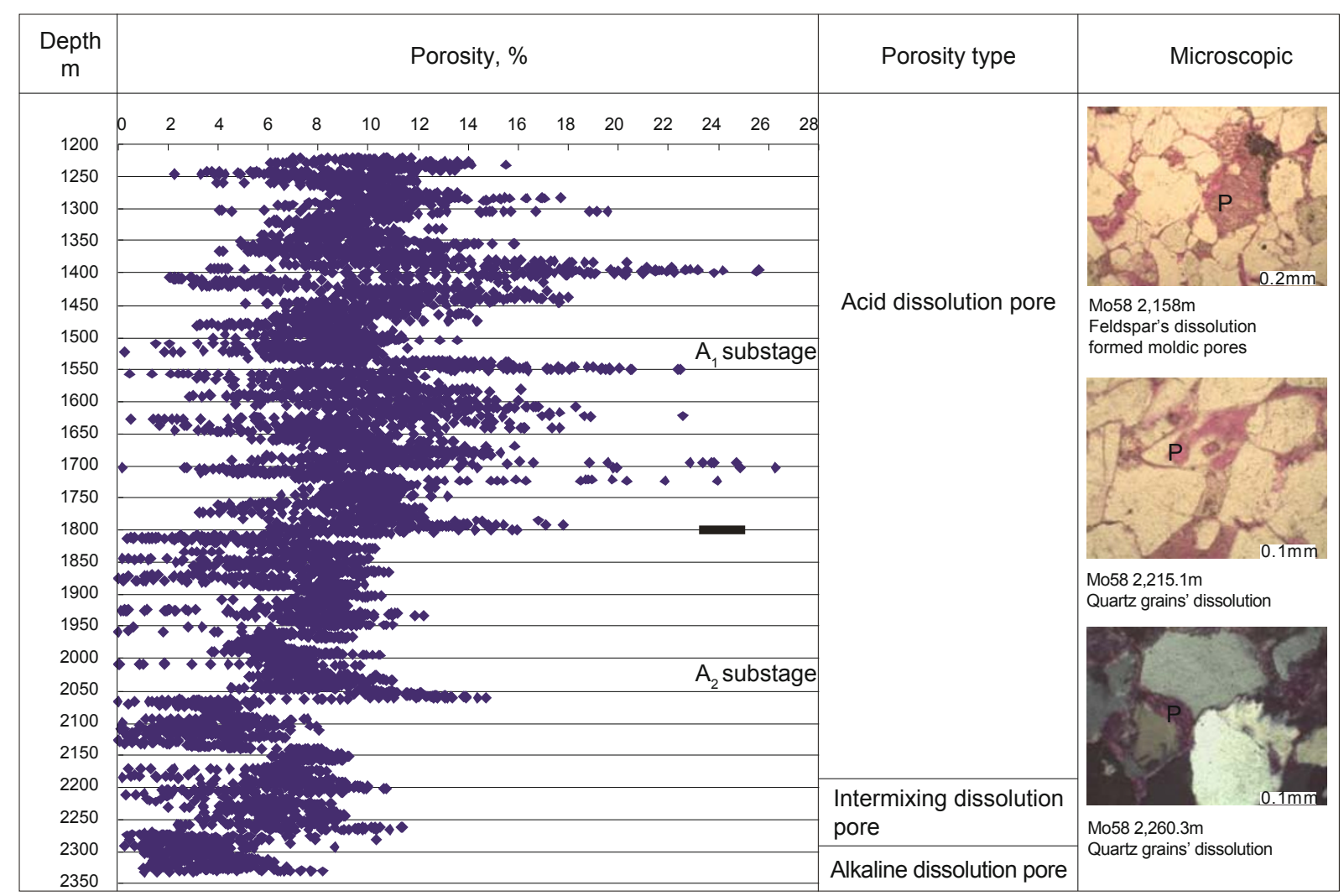

Fig. 6 Vertical evolution of porosity of different genetic types in the Moxi Gas Field

sedimentary environment for the overlying Xujiahe Formation (Fig. 2). On the other hand, the Leikoupo paleo-hills lack $\mathrm{T}_{3} \mathrm{x}^{1}$, which accelerates the invasion of alkaline fluid into $\mathrm{T}_{3} \mathrm{x}^{2}$. With the alkaline environment of limestone, dolomite, and evaporite below, alkaline diagenesis occurred in the $\mathrm{T}_{3} \mathrm{x}^{2}$ in the Himalayan period.

If an alkaline environment was available, cross-formation flow would cause invasion of the alkaline fluids into the $\mathrm{T}_{3} \mathrm{x}^{2}$.

\subsection{Cross-formation flow}

The $\mathrm{T}_{3} \mathrm{x}$ in the study area is a set of terrigenous clastic rocks of continental facies with a large sedimentary thickness. The stratum is the thickest in the west, up to $3,000 \mathrm{~m}$, and gradually decreases towards east, south, and north and is only $300-500 \mathrm{~m}$ in the east. The reason for the thickness change is the rapid lateral change of the terrestrial strata. The Jurassic is a set of fluvial clastics with a thickness of 2,000-3,000 m (Wang et al, 2001) and consists of the Ziliujing, Qianfoyan, Shaximiao, Suining, and Penglaizhen formations from bottom to top (Fig. 2).

The component contributions and correlations of $\mathrm{K}^{+}$, $\mathrm{Na}^{+}, \mathrm{Ca}^{2+}, \mathrm{Mg}^{2+}, \mathrm{Br}^{-}$, and $\mathrm{Cl}^{-}$in the fluid, the carbon and oxygen isotopes of the minerals and the hydrogen and oxygen isotopes of the water of the upper Triassic and Jurassic in the basin revealed that the fluid of the basin is regionally of mixed origin ( $\mathrm{Li}$ et al, 2001). The geochemical characteristics of the elements in the fluid indicated that there was a crossformation flow of the fluid on a large scale in the region.
The fluid of the upper Triassic $\mathrm{T}_{3} \mathrm{x}^{2}$ and $\mathrm{T}_{3} \mathrm{x}^{4}$ layers entered the permeable Jurassic Ziliujing, Qianfoyan, and Shaximiao formations across the impermeable $\mathrm{T}_{3} \mathrm{x}^{3}$ and $\mathrm{T}_{3} \mathrm{x}^{5}$ layers.

The cross-formation flow was not only in the strata of the Jurassic and the upper Triassic, but also in the strata of the Leikoupo Formation and the upper Triassic (Xu et al, 2004). The alkaline fluid of the Leikoupo Formation would flow into the sandstones of the upper Triassic reservoir. The pattern of the cross-formation flow is shown in Fig. 7.

Research shows that the main migration passage of the fluid is faults and the micro-fracture system among them $(\mathrm{Xu}$ et al, 2001).

\subsection{Passage of cross-formation flow}

The passages of cross-formation flow are faults and microfractures. Due to the lack of Jurassic source rocks, the gas in the Jurassic red beds in the Western Sichuan Foreland Basin is mainly from the source rocks of the upper Triassic (Liu et al, 2005). Because of the densification of the formation in the upper Triassic, Jurassic, and the Leikoupo and Jialingjiang formations of the middle Triassic, faults and micro-fractures are the main passages for the migration of the fluid from the Leikoupo and Jialingjiang formations and the gas from the Xujiahe Formation to the shallower layers. The characteristics of the faults and micro-fractures are different in different areas.

\subsubsection{Foreland thrust belt}

Faults and micro-fractures are well developed in the 


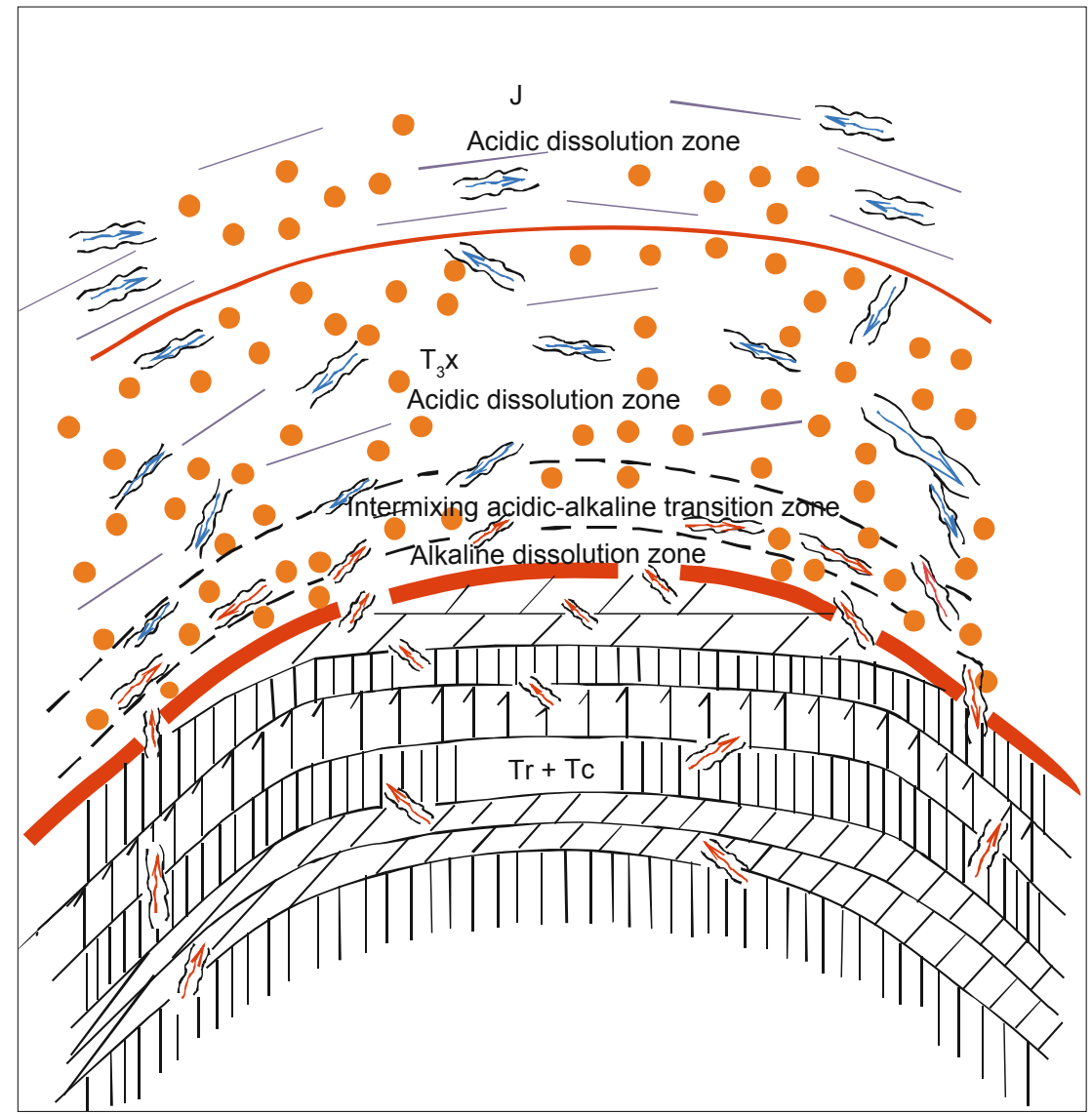

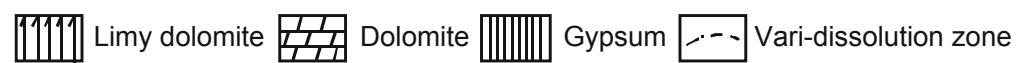

Fracture $\square$ Acidic fluid migration $\square$ Alkaline fluid migration $\square$ Formation boundary

$\mathrm{T}_{3} \mathrm{x}$ : Xujiahe Formation Tr: Leikoupo Formation Tc: Jialingjiang Formation J: Jurassic

Fig. 7 Pattern of cross-formation flow of fluid from $\operatorname{Tr}$ to $\mathrm{T}_{3} \mathrm{x}$ and to the Jurassic in the Western Sichuan Foreland Basin

Longmen and Micang-Daba Mountains thrust belt. The distribution and intensity of micro-fractures are mainly influenced by the tectonic stress belt and the toughness of the rocks. In the folded structure area, the rock deformation has higher intensity in the axial region than at the limb. As a result, the axial region has the most developed fractures. The area near the fractured zone is the favored region for the development of induced fractures (Du et al, 2006).

\subsubsection{Gentle tectonic area at the uplift}

The Leikoupo paleo-hills is an area that had little tectonic activity at the uplift of the basin. The formation above the paleo-hills has different characteristics from the other areas in the basin (Luo and Wang, 1996). In the process of filling the $\mathrm{T}_{3} \mathrm{x}$, the thickness of the sediment on the top of the paleohills was very thin due to erosion, but it was thick in the peripheral area. On the other hand, due to differential loading caused by the varying thickness of the sediment, the original slope can develop at the ramp region of the paleo-hills where the syndepositional faults and fractures can also develop. The formations influenced by the paleo-hills are the $\mathrm{T}_{3} \mathrm{x}^{2}$ and $\mathrm{T}_{3} \mathrm{x}^{4}$ layers.

After the late Indo-China orogeny at the Qinling and Songpan-Ganzi orogenic belts, two giant tectonic thrust belts, Longmen Mountain and Micang-Daba Mountain, developed. They formed the combined layout composed of the orogenic belt and mountain thrust system at the basin rim and within the basin. In this complex combination, the gentle tectonic area of the basin was located between the Longmen and Micang-Daba tectonic thrust belts. This configuration led to a shear by the two adjacent stress belts, resulting in the development of tectonic fractures. Due to the different compressive resistances of coal clastics and terrigenous clastics, diagenetic fractures developed well. As a result of the differential compaction and tectonic stress, fractures developed very well in this gas field.

The upper Triassic formation experienced three periods of thrust movement during the Indo-China, Yanshan, and Himalayan epochs. In the western area, the fractures mainly formed in the Indo-China and Yanshan epochs. In the central slope and uplift area (Fig. 8), the fractures mainly formed in the Yanshan and Himalayan epochs.

\subsection{Evidence for cross-formation flow}

At a depth of 2,202.5 $\mathrm{m}$ in the Mo58 well in the Moxi area, the homogenization temperature of inclusions in carbonate cements has a wide range, from $106^{\circ} \mathrm{C}$ to $157^{\circ} \mathrm{C}$ 


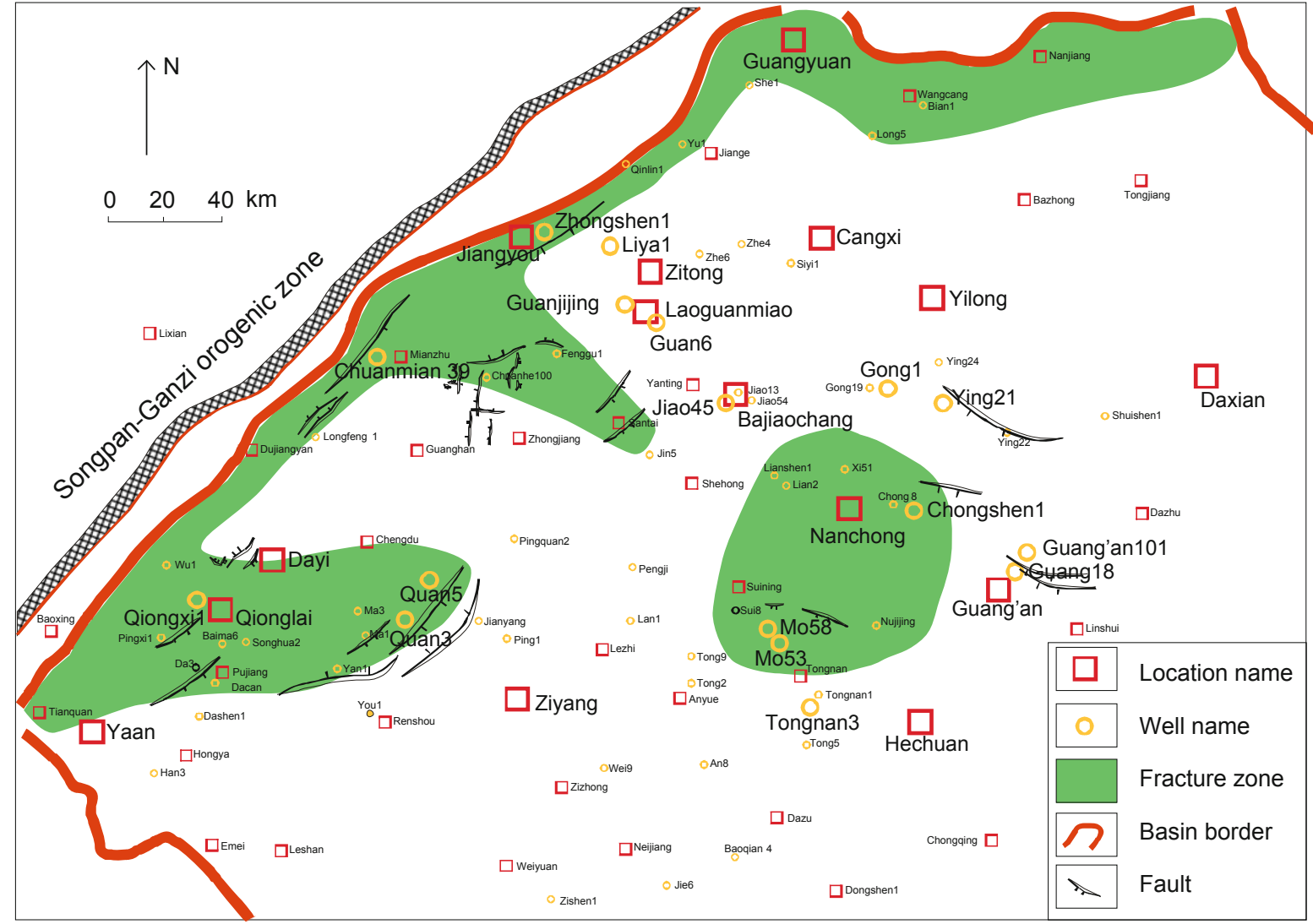

Fig. 8 Distribution of micro-fractures and alkaline diagenesis area (shadow) in the $T_{3} \mathrm{x}$ of the Western Sichuan Foreland Basin

(Table 2). There are three main temperature intervals, i.e., the $\mathrm{T}_{3} \mathrm{x}^{2}$ layer (Yang and Li, 2004), the depth corresponding $100{ }^{\circ} \mathrm{C}-110^{\circ} \mathrm{C}, 120{ }^{\circ} \mathrm{C}-130{ }^{\circ} \mathrm{C}$, and $130{ }^{\circ} \mathrm{C}-140{ }^{\circ} \mathrm{C}$. to $106{ }^{\circ} \mathrm{C}$ is $3,127 \mathrm{~m}$. This implies that the fluid of incluAccording to the geothermal gradient of $2.6{ }^{\circ} \mathrm{C} / 100 \mathrm{~m}$ sions did not come from the $\mathrm{T}_{3} \mathrm{x}^{2}$ layer itself but from even (Wang et al, 1998) and a surface temperature of $24.7^{\circ} \mathrm{C}$ in deeper strata.

Table 2 Temperatures inferred from the carbonate cement inclusions of the Mo58 well

\begin{tabular}{|c|c|c|c|c|c|c|c|}
\hline Lithology & Location, $\mathrm{m}$ & $\begin{array}{l}\text { Occurring } \\
\text { mineral }\end{array}$ & $\begin{array}{c}\text { Original/ } \\
\text { secondary } \\
\text { inclusion }\end{array}$ & $\begin{array}{l}\text { Inclusion } \\
\text { type }\end{array}$ & $\begin{array}{c}\text { Inclusion } \\
\text { size, } \mu \mathrm{m}\end{array}$ & $\begin{array}{c}\text { Homogenization } \\
\text { phase state }\end{array}$ & $\begin{array}{c}\text { Temperature, } \\
{ }^{\circ} \mathrm{C}\end{array}$ \\
\hline \multirow{17}{*}{$\begin{array}{l}\text { Medium-fine } \\
\text { sandstone }\end{array}$} & \multirow{17}{*}{2202.5} & \multirow{17}{*}{$\begin{array}{l}\text { Cement } \\
\text { of late } \\
\text { calcite }\end{array}$} & \multirow{17}{*}{ Original } & \multirow{17}{*}{$\begin{array}{l}\text { Hydrocarbon- } \\
\text { bearing brine } \\
\text { inclusion }\end{array}$} & $2 \times 3$ & \multirow{17}{*}{ Liquid phase } & 133 \\
\hline & & & & & $2 \times 4$ & & 135 \\
\hline & & & & & $3 \times 4$ & & 141 \\
\hline & & & & & $3 \times 5$ & & 135 \\
\hline & & & & & $2 \times 3$ & & 152 \\
\hline & & & & & $3 \times 4$ & & 148 \\
\hline & & & & & $3 \times 5$ & & 147 \\
\hline & & & & & $2 \times 4$ & & 157 \\
\hline & & & & & $3 \times 4$ & & 119 \\
\hline & & & & & $3 \times 5$ & & 122 \\
\hline & & & & & $2 \times 3$ & & 102 \\
\hline & & & & & $2 \times 4$ & & 106 \\
\hline & & & & & $2 \times 5$ & & 106 \\
\hline & & & & & $3 \times 4$ & & 106 \\
\hline & & & & & $2 \times 3$ & & 107 \\
\hline & & & & & $2 \times 5$ & & 109 \\
\hline & & & & & $5 \times 7$ & & 114 \\
\hline
\end{tabular}


The maximum depth corresponding to $130^{\circ} \mathrm{C}$ is $4,050 \mathrm{~m}$ and that corresponding to $140{ }^{\circ} \mathrm{C}$ is $4,435 \mathrm{~m}$. The thickness of the alkaline strata consisting of dolomites and gypsum in the $\mathrm{Tc}$ and $\mathrm{Tr}$ is from 300 to $1,400 \mathrm{~m}$. This means that there must have been some alkaline fluids of the Tc and Tr invading into the $\mathrm{T}_{3} \mathrm{x}^{2}$ layer. In this process, the faults and micro-fractures played very important roles in the migration of the alkaline fluid.

\section{Conclusions}

In the study area, the acid dissolution of unstable components is the main source of secondary porosity, and in some regions dissolution of quartz grains increases the storage space of the $T_{3} x$ reservoir. The stratigraphic configuration is a base for quartz dissolution, the fracture system of faults is the passage, and the cross-formation flow of fluid in the Himalayan epoch is the outside driving force. Quartz dissolution is an important diagenetic event in the study area. Quartz can be directly dissolved in the process of burial and diagenetic evolution of the reservoir, and the formation water that caused the quartz to dissolve came from the underlying Leikoupo and Jialingjiang formations. The dissolution of quartz gives a new explanation for the origin of the pores in the reservoir and enriches the knowledge of the genesis of secondary porosity in the reservoir.

\section{Acknowledgements}

This research is co-funded by the National Natural Science Foundation of China (No.40672078) and China National Petroleum Corporation (CNPC). Dr. Hongbo Lu in Shell International Exploration and Production read the manuscript and gave some constructive suggestions, for which we are grateful.

\section{References}

Bjørkum P A, Oelkers E H, Nadeau P H, et al. Porosity prediction in quartzose sandstones as a function of time, temperature, depth, stylolite frequency, and hydrocarbon saturation. AAPG Bulletin. 1998. 82(4): 637-648

Bloch S. Secondary porosity in sandstones: significance, origin, relationship to subaerial unconformities, and effect on predrill reservoir quality prediction, in M. D. Wilson, ed., Reservoir Quality Assessment and Prediction in Clastic Rocks. SEPM Short Course 30. 1994. 137-160

Bloch S, Lander R H and Bonnell L. Anomalously high porosity and permeability in deeply buried sandstone reservoirs: Origin and predictability. AAPG Bulletin. 2002. 86(2): 301-328

Brady P V. Silica surface chemistry at elevated temperatures. Geochimica et Cosmochimica Acta. 1992. 56(7): 2941-2946

Dong $\mathrm{Z} \mathrm{H}$. Model for diagenesis and porosity evolution of the dense sandstones from the Xujiahe Formation in Western Sichuan Basin. Sedimentary Facies and Palaeogeography. 1994. 14(2): 33-40 (in Chinese)

Du Y B, Ji H C, Wu Y Y, et al. Single factor diagenetic facies analysis of tight reservoir in western Sichuan foreland basin. Acta Petrolei Sinica. 2006. 27(2): 48-52 (in Chinese)

Fang C L, Niu J Y and Qiao H S. Petroleum Geology in Deep Formations of Eastern China. Beijing: Petroleum Industry Press. 2002. 149-253 (in Chinese)
Giles M R. Diagenesis: A Quantitative Perspective. Dordrecht: Kluwer Academic Publishers. 1997. 526

Hiemstra T and Van Riemsdijk W H. Multiple activated-complex dissolution of metal (hydr) oxides: a thermodynamic approach applied to quartz. Journal of Colloid and Interface Science. 1990. 136(1): 132-150

Hunt J M. Generation and migration of petroleum from abnormally pressured fluid compartments. AAPG Bulletin. 1990. 74(1): 1-12

Jiang Z X, Tian J J, Chen G J, et al. Sedimentary characteristics of the Upper Triassic in western Sichuan foreland basin. Journal of Palaeogeography. 2007. 9(2): 143-154 (in Chinese)

Knauss K G and Wolery T J. The dissolution kinetics of quartz as a function of $\mathrm{pH}$ and time at $70{ }^{\circ} \mathrm{C}$. Geochimica et Cosmochimica Acta. 1988. 52(1): 43-53

Li J C, Liu S G, Xu G S, et al. Cross-formational migration of fluids in the compact sandstone-type gas field, western Sichuan foreland basin. Earth and Environment. 2001. 29(4): 73-81 (in Chinese)

Liu S G, Li G R, Li J C, et al. Fluid cross formation flow and gas explosion accumulation in western Sichuan foreland basin, China. Acta Geologica Sinica. 2005. 79(5): 690-699 (in Chinese)

Luo Q H and Wang S Q. Research on natural gas enrichment conditions of the main coal-bearing strata of Triassic in the centre-west part of Sichuan Basin. Natural Gas Industry. 1996. 16(supplement): 40-54 (in Chinese)

Mu S G and Zhang Y M. Reservoir pore evolution under the control of diagenesis and stage. Journal of Southwest Petroleum Institute. 1994. 16(3): 22-27 (in Chinese)

Oelkers E H, Bjørkum P A and Murphy W M. The mechanism of porosity reduction, stylolite development and quartz cementation in North Sea sandstones, in Y. K. Kharaka and A. S. Maest, eds., Proceedings, International Symposium on Water-Rock Interaction, Rotterdam, Balkema. 1992. 2: 1183-1186

Osborne M J and Swarbrick R E. Diagenesis in North Sea HPHT clastic reservoirs - consequences for porosity and overpressure prediction. Marine and Petroleum Geology. 1999. 16(4): 337-353

Pang M and Zheng J M. Diagenesis Study of Clastic Reservoirs. Wuhan: Publishing House of China University of Geosciences. 1989. 81-84, 121-129 (in Chinese)

Qiu L W and Jiang Z X. Alkaline diagenesis of terrigenous clastic rocks. Beijing: Geological Publishing House. 2006. 1-2 (in Chinese)

Riley R A, Wicks J and Thomas J. Cambrian-Ordovician Knox production in Ohio: Three case studies of structural-stratigraphic traps. AAPG Bulletin. 2002. 86(4): 539-555

Southwick J G. Solubility of silica in alkaline solutions: Implications for alkaline flooding. SPE Journal. 1985. 25(6): 857-864

Sun Z L, Huang S J, Zhang Y X, et al. Origin and diagenesis of authigenic chlorite within the sandstone reservoirs of Xujiahe Formation, Sichuan Basin, China. Acta Sedimentologica Sinica. 2008. 26(3): 459-468 (in Chinese)

Sun Z L. Study of clay minerals of the Xujiahe sandstone reservoir Formation in the areas of Xiaoquan, Xinchang and Hexingchang. PhD Thesis. 2006. 39-49 (in Chinese)

Surdam R C, Boese S W and Crossey L J. The chemistry of secondary porosity. In: McDonald D A, Surdam R C (eds.), Clastic Diagenesis. The American Association of Petroleum Geologists, Tulsa, Oklahoma. 1985. 127-150

Surdam R C, Crossey L J, Hagen E S, et al. Organic-inorganic interactions and sandstone diagenesis. AAPG Bulletin. 1989. 73(1): $1-23$

Wang S Q, Luo Q H, Deng H B, et al. Characteristics of forming Jurassic gas reservoirs in the west part of Sichuan Basin. Natural Gas Industry. 2001. 21(2): 1-8 (in Chinese)

Wang Y G, Yu X F, Yang Y, et al. Applications of fluid inclusions in the study of paleo-geotemperature in Sichuan Basin. Earth Science- 
Journal of China University of Geosciences. 1998. 23(3): 285-288 (in Chinese)

Wilkinson M, Darby D, Haszeldine R S, et al. Secondary porosity generation during deep burial associated with overpressure leak-off: Fulmar Formation, United Kingdom Central Graben. AAPG Bulletin. 1997. 81(5): 803-813

$\mathrm{Xu} \mathrm{B} \mathrm{M}$ and $\mathrm{Lu} \mathrm{B}$. The study of diagenetic carbonate in siliciclastic rock and its control on the reservoir. Acta Sedimentologica Sinica. 1994. 12(3): 56-66 (in Chinese)

Xu G S, Liu S G, Li G R, et al. Phase state evolution in the cross formational flow of natural gas in the western Sichuan foreland basin. Journal of Chengdu University of Technology. 2001. 28(4): 383-388 (in Chinese)

Xu H, Wei G Q, Tang D Z, et al. The feature analysis and its geological significance of organic fluid inclusions in the west Sichuan. Geoscience. 2004. 18(3): 360-365 (in Chinese)
Yang $\mathrm{H} \mathrm{H}$ and $\mathrm{Li} \mathrm{Z} \mathrm{H.} \mathrm{Development} \mathrm{of} \mathrm{geothermal} \mathrm{pool} \mathrm{deduced} \mathrm{from}$ old thermal current values and denudation quantity - by the example of Well 100 at Chuanhe in Sichuan Basin. Acta Geologica Sichuan. 2004. 24(3): 180-184 (in Chinese)

You $\mathrm{J}$ and Zheng $\mathrm{J}$ M. Factors affecting the reservoir physical properties of deep strata in the Huanghua Depression. Geoscience. 1999. 13(3): 350-354 (in Chinese)

Zhang $\mathrm{S}$ and $\mathrm{Li} \mathrm{T}$ J. Research advance in dissolution kinetics of quartz. Global Geology. 1996. 15(4): 8-13 (in Chinese)

Zheng $\mathrm{J}$ M and Ying F X. Reservoir characteristics and diagenetic model of sandstone intercalated in coal-bearing strata (acid water medium). Acta Petrolei Sinica. 1997. 18(4): 19-24 (in Chinese)

Zhuang S S, Zuo Y C and Li Q. Diagenesis and predicting secondary pores for second member of Dainan Formation in Qintong Depression of North Jiangsu province. Journal of Mineralogy and Petrology. 1998. 18(4): 64-71 (in Chinese) 